\title{
Polydextrose as Dietary Fiber: Hydrolysis by Digestive Enzyme and Its Effect on Gastrointestinal Transit Time in Rats
}

\author{
Tsuneyuki OKU, ${ }^{1, *}$ Yasuhiro FUJII, ${ }^{2}$ and Hiroshi OKAMATSU ${ }^{2}$ \\ ${ }^{1}$ Department of Nutrition, Faculty of Medicine, The University of \\ Tokyo, Bunkyo-ku, Tokyo 113, Japan \\ ${ }^{2}$ Saga Research Institute, Otsuka Pharmaceutical Co., Ltd., \\ Higashisefuri, Saga 842-01, Japan
}

(Received January 30, 1991)

\begin{abstract}
Summary In order to investigate the physiological action of Polydextrose as a dietary fiber, we fed rats $3 \%$ Polydextrose diet containing either pectin or cellulose for 15 days. The effects of Polydextrose on fecal weight and gastrointestinal transit time were observed, and digestibility and the inhibitory effect of the fiber on intestinal digestive enzymes were examined. Polydextrose was partially hydrolyzed by rat intestinal mucosal homogenate, and liberated glucose increased depending on incubation time. However, Polydextrose had no inhibitory effect on the activity of disaccharidases. The combination of Polydextrose and either pectin or cellulose significantly increased fecal weight and evidently shortened transit time. The effect of Polydextrose supplementation on tissue weight was found in the cecum only, and not in other tissues. The concentration of serum constituents such as total and free cholesterol, triacylglycerol, phospholipid, and glucose was not affected by Polydextrose ingestion. These results suggest that Polydextrose partially demonstrates the dietary fiber actions such as increase in fecal volume and weight, shortening of transit time, and softening of feces.
\end{abstract}

Key Words: Polydextrose, dietary fiber, fecal weight, transit time, disaccharidase

Polydextrose, synthesized by random bonding of glucose, sorbitol, and citric acid (89:10:1) under high pressure and partial vacuum, was developed as a low-energy bulking agent in the U.S. [1]. It is a heterogenous compound with a variable molecular weight ranging from several hundreds to several tens of thou-

\footnotetext{
*To whom correspondence should be addressed.
} 
sands, and averaging about 1,500 [1]. Polydextrose as a dietary fiber is considered to be resistant to digestive enzymes, because it is a low-energy bulking agent $[2,3]$. However, it is not clear whether Polydextrose demonstrates other dietary fiber actions such as increase of fecal volume and weight, shortening of transit time, softening of feces, and improvement of intestinal microflora.

The purpose of this study was to clarify whether Polydextrose can show some of the physiological actions of dietary fiber [4]. In preliminary tests, excessive consumption of Polydextrose often caused diarrhea. Accordingly, in this study the physiological action of Polydextrose was observed through combination with either pectin or cellulose, which are similar natural dietary fiber sources.

\section{MATERIALS AND METHODS}

Animals and diets. Fifty male Sprague-Dawley rats (Charles River Japan Inc., Atsugi, Japan), weighing about $180 \mathrm{~g}$, were fed a basal fiber-free diet (control diet) for 10 days, and then divided randomly into 5 groups and housed individually in suspended wire mesh-bottomed cages. They were maintained at a temperature of $23 \pm 0.5^{\circ} \mathrm{C}$ and a humidity of $55 \pm 10 \%$ in air-conditioned animal facilities on a daily photo period of $12 \mathrm{~h}$ light (19:00-7:00) and dark (7:00-19:00). The composition of diets used in this study is shown in Table 1.

Four experimental groups received fiber-supplemented diets prepared by partial substitution of the $\alpha$-corn starch in the basal fiber-free diet by the dietary fiber indicated. Pectin (LM-101AS, methoxylation 34\%, Copenhagen Pectin Factory Ltd., Copenhagen) or cellulose (Avicel PH-101, Asahi Chemical Industry Co. Ltd., Tokyo) was added to the diet at a final concentration of $3 \%(w / w)$. To observe the additional effect of Polydextrose (A-type, Pfizer K.K., Tokyo), we further added it, at the same level, to the diet containing either pectin or cellulose. For equalization of nutrient intake except for dietary fiber and corn starch, $15 \mathrm{~g}$ of diet/day was given between 9:00 and 13:00 to each animal for 15 days. Free access to water was allowed. Body weights were recorded every day, and feces and urine were collected for 2 days, day 9 and day 10, during the experiment. All rats were

Table 1. Composition of diets $(\%, w / w)$.

\begin{tabular}{lccccc}
\hline Constituent & Control & Pectin & $\begin{array}{c}\text { Pectin } \\
\text { +Polydextrose }\end{array}$ & Cellulose & $\begin{array}{c}\text { Cellulose } \\
\text { + Polydextrose }\end{array}$ \\
\hline$\alpha$-Corn starch & 19.0 & 16.0 & 13.0 & 16.0 & 13.0 \\
Pectin & - & 3.0 & 3.0 & - & - \\
Cellulose & - & - & - & 3.0 & 3.0 \\
Polydextrose & - & - & 3.0 & - & 3.0 \\
Others $^{\mathrm{a}}$ & 81.0 & 81.0 & 81.0 & 81.0 & 81.0 \\
\hline
\end{tabular}

Composition of basal diet was slightly modified from that of AIN-76. ${ }^{a}$ Casein (20\%), DL-methionine $(0.3 \%)$, sucrose $(51.2 \%)$, corn oil $(5.0 \%)$, vitamin mixture $(1.0 \%)$, salt mixture (3.5\%). Pectin, cellulose and Polydextrose were added at $3 \%$ concentration each. Vitamin mixture and salt mixture are AIN-76 compositions [5]. 
killed in the afternoon on day 16.

In vitro hydrolysis of Polydextrose by intestinal mucosal homogenates. Five male Sprague-Dawley rats (Charles River Japan Inc., Tokyo), weighing about $200 \mathrm{~g}$, were raised on a basal fiber-free diet (control diet in Table 1) for 1 week. After the animals had been killed and the small intestine washed well, a mucosal homogenate $(10 \%)$ was prepared with a 9-fold volume of physiological saline. Equal volumes $(100 \mu 1)$ of homogenate adequately diluted and Polydextrose solution $(2 \%$ or $10 \%)$ were mixed and incubated for $0-60 \mathrm{~min}$ at $37^{\circ} \mathrm{C}$. Glucose liberated from the Polydextrose was measured by the Tris-buffered glucose oxidase method [6].

In vitro experiment on effect of Polydextrose on intestinal disaccharidase activities. The activities of sucrase, maltase, and isomaltase of intestinal mucosal homogenate were determined in the presence or absence of Polydextrose by Dahlqvist's method [6] using Tris-buffered glucose oxidase. Equal volumes (100 $\mu 1)$ of substrate and homogenate adequately diluted were mixed and incubated at $37^{\circ} \mathrm{C}$ for $30 \mathrm{~min}$ in the presence or absence of $10 \%$ Polydextrose solution $(50 \mu 1)$. The hydrolysis was terminated by the addition of $2 \mathrm{ml}$ of Tris-buffered glucose oxidase reagent; and, at the same time, color production, dependent on glucose concentration, was started. The protein concentration was measured by the method of Lowry et al. [7] using bovine serum albumin as a standard.

Gastrointestinal transit time measurement. For measurement of gastrointestinal transit time, carmine red as a marker was added to each test diet at concentration of $0.5 \%$ [8]. The diet with marker was given to rats at 9:00 a.m. on day 15 of the experiment, and fecal excretion of the marker was checked every hour. The interval between the start of feeding and the first detection of marker was defined as the gastrointestinal transit time.

Fecal collection and measurement. Feces were collected twice a day (4:00 p.m. and 9:00 a.m.). Immediately after collection, the wet weight was measured and the feces placed in a polyethylene vial with a stopper. Fresh feces obtained for 2 days, day 9 and day 10 , were pooled and stored at $-20^{\circ} \mathrm{C}$. After the feces had been dried at $110^{\circ} \mathrm{C}$ for $24 \mathrm{~h}$, the weight was measured again as dry weight. The cecal contents were not added to the fecal weight.

Tissue sampling and measurement. The animals were anesthesized with diethylether and the abdominal cavity was opened in the afternoon on day 16 and blood was collected through abdominal inferior caval puncture to obtain serum. Then, liver, kidney, heart, small intestine, cecum and colon were removed, cleaned, and weighed. The length of the small intestine and of the colon was measured. Several serum constituents such as total and free cholesterol, triacylglycerol, phospholipid, and glucose were assayed by autoanalyzer (OLYMPUS AU-500, Olympus Optcal Co. Ltd., Tokyo) [9].

Statistical analysis. The statistical significance of differences between values was tested by one-way analysis of variance followed by Tukey's multiple-range test.

Vol. 11, No. 1, 1991 


\section{RESULTS}

\section{In vitro experiments}

Hydrolysis of Polydextrose by intestinal mucosal homogenates. Figure 1 shows the time course of Polydextrose hydrolysis by rat intestinal mucosal homogenate. The time course of Polydextrose hydrolysis was not linear, and the hydrolyzing activity was lower than that of sucrase, which is about one-fifteenth that of maltase. The increase in the amount of glucose liberated from Polydextrose with time indicates that Polydextrose used in this study contains a few, but not many, $\alpha-1,4$ and/or $\alpha-1,6$ linkages of glucose hydrolyzable by digestive enzyme. Further, the time-dependent increase of difference in hydrolyzing activity between sucrose and Polydextrose suggests that Polydextrose contains very little but detectable amount of the Polydextrose fragments of low molecular weight which is hydrolyzed by digestive enzyme. It is clear that high molecular weight Polydextrose is abundant in the substrate solution, because more than $60 \%$ of the Polydextrose ingested is excreted in the feces in intact form $[2,3]$. It is also clear that Polydextrose includes both absorbable and digestible portions, since the energy drived from Polydextrose is considered to be about $1 \mathrm{kcal} / \mathrm{g}[2,3]$.

Effect of Polydextrose on intestinal disaccharidase activity. The activity of sucrase, maltase, or isomaltase was not affected by the addition of Polydextrose to the in vitro assay system (Table 2). Maltitol and maltose act competitively for binding sites on maltase [10]. However, the result of this experiment indicates that Polydextrose does not have any inhibitory effect on activities of disaccharidases such as maltase, sucrase, and isomaltase in the small intestinal mucosa.

\section{In vivo experiments}

Body weight gain and food intake. The dietary fiber supplement did not have any significant effect on body weight gain (Table 3) during the period of this experiment in spite of the fact that it is a reduced energy materials. The food intake for 15 days was slightly, but significantly, lower in the pectin group than in the control group. Although all the animals received equal amounts of food, food intake was slightly different among the 5 groups, due mainly to dropped or leftover food.

Fecal weight and gastrointestinal transit time. All rats feeding fibersupplemented diets showed significantly increased wet and dry feces weights compared with the control group (Fig. 2). The addition of Polydextrose to either pectin- or cellulose-supplemented diet further increased wet and dry weights of the feces. In particular, Polydextrose increased the water-holding capacity of feces. This demonstrates that the feces of rats receiving Polydextrose-supplemented diet containing dietary fiber is softer.

In general, an increase in fecal volume directly shortens gastrointestinal transit time [4], although the effects are dependent on the physical and chemical prop- 


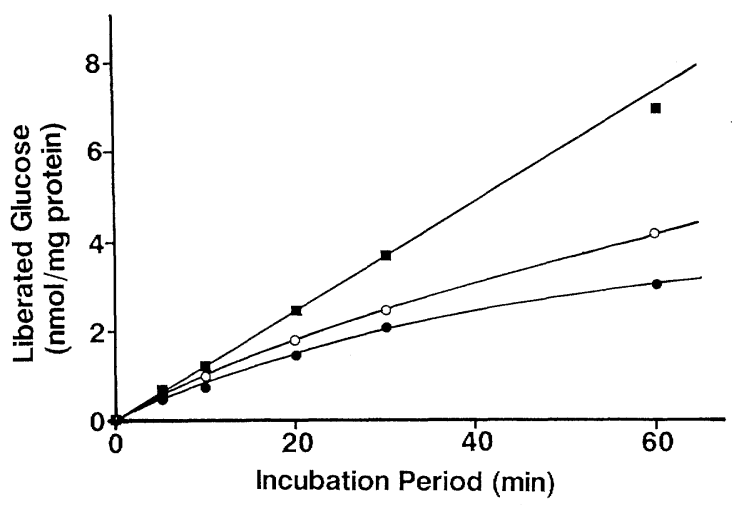

Fig. 1. Time course of Polydextrose hydrolysis by rat intestinal mucosal homogenate. The substrate solution $(100 \mu 1)$ as $56 \mathrm{~mm}$ sucrose or $2 \%$ or $10 \%$ Polydextrose was incubated at $37^{\circ} \mathrm{C}$ for $0-60 \mathrm{~min}$ with the same volume of adequately diluted intestinal mucosal homogenate. The liberated glucose was measured by the Tris-buffered glucose oxidase method [6]. $-56 \mathrm{~mm}$ sucrose; $\bullet-2 \%$ Polydextrose; $\bigcirc-\circ, 10 \%$ Polydextrose.

Table 2. Effect of Polydextrose on rat intestinal disaccharidase activities.

\begin{tabular}{cccc}
\hline $\begin{array}{c}\text { Polydextrose } \\
\text { concentration } \\
(\%)\end{array}$ & Sucrase & Maltase & Isomaltase \\
& \multicolumn{2}{c}{ (nmol substrate hydrolyzed/mg protein $/ \mathrm{h})$} \\
\hline 0 & $3.9 \pm 0.12$ & $11.8 \pm 0.35$ & $8.5 \pm 0.31$ \\
2 & $3.8 \pm 0.18$ & $13.2 \pm 0.42$ & $8.0 \pm 0.95$ \\
10 & $3.9 \pm 0.31$ & $13.1 \pm 0.48$ & $8.0 \pm 0.42$ \\
\hline
\end{tabular}

Intestinal mucosal homogenate of rats fed a basal fiber-free diet for one week was used to determine the disaccharidase activities. Equal volumes $(100 \mu 1)$ of substrate solution and mucosal homogenate were incubated at $37^{\circ} \mathrm{C}$ for $30 \mathrm{~min}$ in the presence or absence of Polydextrose. Results represent means \pm SD of 5 rats/group.

Table 3. Body weight gain and food intake.

\begin{tabular}{lcccc}
\hline Groups & $\begin{array}{c}\text { Initial body } \\
\text { weight } \\
(\mathrm{g})\end{array}$ & $\begin{array}{c}\text { Final body } \\
\text { weight } \\
(\mathrm{g})\end{array}$ & $\begin{array}{c}\text { Body weight } \\
\text { gain } \\
(\mathrm{g})\end{array}$ & $\begin{array}{c}\text { Food } \\
\text { intake } \\
(\mathrm{g})\end{array}$ \\
\hline Control & $218.5 \pm 6.9$ & $285.3 \pm 9.4$ & $66.8 \pm 3.0$ & $226.2 \pm 1.3$ \\
3\% Pectin & $220.8 \pm 6.6$ & $284.4 \pm 11.2$ & $66.3 \pm 10.3$ & $222.6 \pm 6.0^{*}$ \\
3\% Pectin + & $220.9 \pm 5.2$ & $286.2 \pm 8.5$ & $65.3 \pm 5.3$ & $226.2 \pm 0.6$ \\
3\% Polydextrose & & & & \\
3\% Cellulose & $220.7 \pm 5.0$ & $284.5 \pm 8.1$ & $63.8 \pm 8.1$ & $225.2 \pm 1.5$ \\
3\% Cellulose+ & $220.4 \pm 6.1$ & $284.5 \pm 8.9$ & $61.1 \pm 3.7$ & $226.6 \pm 1.9$ \\
3\% Polydextrose & & & & \\
\hline Results represent means \pm SD of 10 rats/group. The body weight gain and food intake are the \\
sum for 15 days. *Significantly different from Control group at $p<0.05$.
\end{tabular}

Vol. 11, No. 1, 1991 


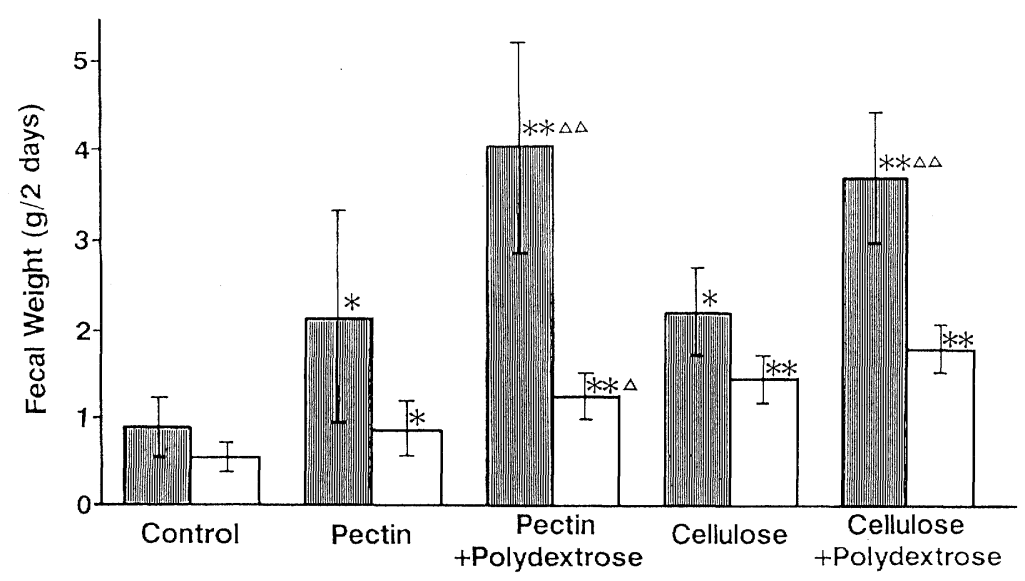

Fig. 2. Effect of Polydextrose on wet and dry fecal weights in the rat. Data represent means of 10 rats/group; and vertical bars, SD. $\mathbb{m}$ mim wet weight (g/2 days); $\square$ dry weight (g/2 days). ${ }^{*}, *$ Significantly different from control group at $p<0.05$ and $p<0.01$, respectively. $\triangle, \Delta \triangle$ Significant difference between Polydextrose-nonsupplemented and -supplemented groups at $p<0.05$ and $p<0.01$, respectively.

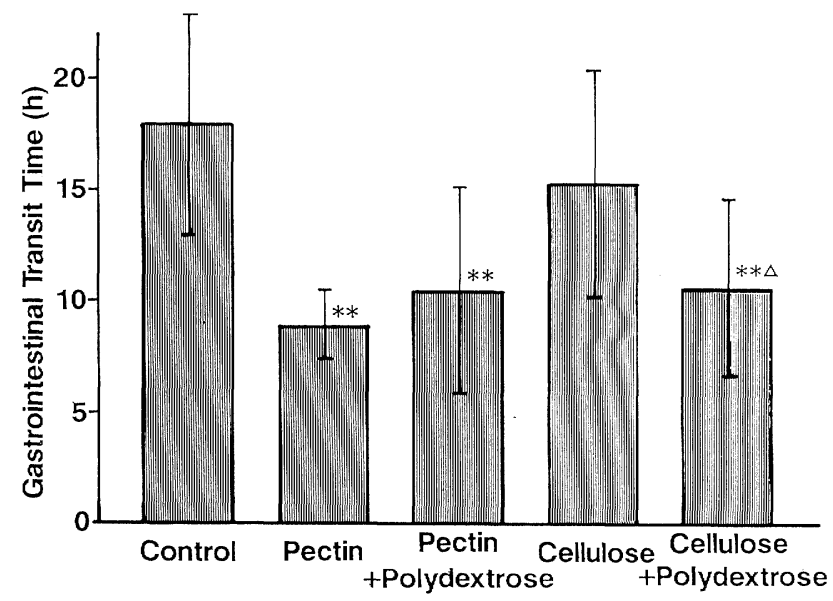

Fig. 3. Effect of Polydextrose on gastrointestinal transit time. Data represent means of 10 rats/group. Vertical bars indicate SD. ${ }^{* *}$ Significantly different from control group at $p<0.01$. ${ }^{\triangle}$ Significantly different from cellulose-supplemented group at $p<0.05$.

erties of the dietary fiber. In this study, the transit time in rats receiving the Polydextrose-supplemented diet containing cellulose was shortened significantly compared with that of control group and of cellulose group (Fig. 3); while the addition of Polydextrose to the pectin-supplemented diet did not further reduce transit time, even though the fecal weight increased significantly. The effect of 
Table 4. Effect of Polydextrose on weight and length of small intestine, cecum, and colon in the rat.

\begin{tabular}{|c|c|c|c|c|c|}
\hline \multirow[b]{2}{*}{ Groups } & \multicolumn{2}{|c|}{ Small intestine } & \multirow{2}{*}{$\begin{array}{l}\text { Cecum } \\
\text { weight } \\
\text { (g) }\end{array}$} & \multicolumn{2}{|c|}{ Colon } \\
\hline & $\begin{array}{l}\text { weight } \\
(\mathrm{g})\end{array}$ & $\begin{array}{l}\text { length } \\
(\mathrm{cm})\end{array}$ & & $\begin{array}{l}\text { weight } \\
\text { (g) }\end{array}$ & $\begin{array}{l}\text { length } \\
(\mathrm{cm})\end{array}$ \\
\hline Control & $5.6 \pm 0.7$ & $109.7 \pm 2.5$ & $0.58 \pm 0.07$ & $1.2 \pm 0.2$ & $17.1+1.0$ \\
\hline 3\% Pectin & $5.8 \pm 0.5$ & $107.8 \pm 10.2$ & $0.67 \pm 0.06^{*}$ & $1.2 \pm 6.0$ & $17.5 \pm 1.1$ \\
\hline $\begin{array}{l}\text { 3\% Pectin }+ \\
\text { 3\% Polydextrose }\end{array}$ & $6.0 \pm 0.4$ & $111.8 \pm 2.7$ & $0.85 \pm 0.01^{* *}$ & $1.3 \pm 0.2$ & $17.8 \pm 0.9$ \\
\hline 3\% Cellulose & $5.5 \pm 0.5$ & $108.0 \pm 4.4$ & $0.58 \pm 0.04$ & $1.2 \pm 0.1$ & $18.0 \pm 1.5$ \\
\hline $\begin{array}{l}3 \% \text { Cellulose }+ \\
3 \% \text { Polydextrose }\end{array}$ & $5.6 \pm 0.4$ & $106.8 \pm 4.4$ & $0.84 \pm 0.08^{* *}$ & $1.1 \pm 0.1$ & $17.8 \pm 1.1$ \\
\hline
\end{tabular}

Results represent means \pm SD of 10 rats/group. ${ }^{* * *}$ Significantly different from control group at $p<0.05$ and $p<0.01$, respectively.

Table 5. Effect of Polydextrose on serum concentrations of total and free cholesterol, triacylglycerol, phospholipid, and glucose in the rat.

\begin{tabular}{lccccc}
\hline Groups & $\begin{array}{c}\text { Total } \\
\text { cholesterol } \\
(\mathrm{mg} / \mathrm{dl})\end{array}$ & $\begin{array}{c}\text { Free } \\
\text { cholesterol } \\
(\mathrm{mg} / \mathrm{dl})\end{array}$ & $\begin{array}{c}\text { Triacyl- } \\
\text { glycerol } \\
(\mathrm{mg} / \mathrm{dl})\end{array}$ & $\begin{array}{c}\text { Phospho- } \\
\text { lipid } \\
(\mathrm{mg} / \mathrm{dl})\end{array}$ & $\begin{array}{r}\text { Glucose } \\
(\mathrm{mg} / \mathrm{dl})\end{array}$ \\
\hline Control & $59 \pm 10$ & $11 \pm 3$ & $36 \pm 8$ & $98 \pm 10$ & $102+18$ \\
3\% Pectin & $65 \pm 13$ & $13 \pm 3$ & $35 \pm 7$ & $104 \pm 16$ & $101 \pm 14$ \\
3\% Pectin+ & $67 \pm 12$ & $13 \pm 4$ & $37 \pm 6$ & $105 \pm 14$ & $98 \pm 16$ \\
$\begin{array}{c}\text { 3\% Polydextrose } \\
\text { 3\% Cellulose }\end{array}$ & $69 \pm 10$ & $13 \pm 2$ & $35 \pm 6$ & $107 \pm 11$ & $91 \pm 13$ \\
3\% Cellulose+ & $70 \pm 17$ & $13 \pm 5$ & $32 \pm 7$ & $103 \pm 16$ & $105 \pm 20$ \\
3\% Polydextrose & & & & & \\
\hline
\end{tabular}

Results represent means \pm SD of 10 rats/group. The serum constituents were measured by an autoanalyzer (OLYMPUS AU-500, Olympus Optcal Co. Ltd.) [9].

Polydextrose on transit time appears to be dependent on the kind of dietary fiber added to the diet. Overall, these results suggest that Polydextrose has the same physiological action as dietary fiber; i.e., it reduces constipation, increases intestinal peristalsis, etc.

Weight and length of small and large intestines. Table 4 shows wet weight and length of small intestine and colon and cecal weight. No significant difference was observed in weight and length of small intestine or colon among all groups. However, except for the cellulose-fed group, the cecal weight increased significantly in fiber-fed groups, compared with that of the fiber-free group. Cecal and colonic enlargement is induced by ingestion of dietary fibers such as cellulose, glucomannan, and pectin $[11,12]$ and nondigestible oligosaccharides such as Neosugar [13] and maltitol [14]. Recovery from tissue enlargement can be achieved by elimination of nondigestible carbohydrates from the diet $[13,15]$. Therefore, it is believed that the cecal and colonic enlargement is a biological 
adaptation. Though not shown in the data, the wet weight of several tissues such as liver, kidney, and heart was not significantly influenced by fiber in the diet.

Analysis of serum constituents. The concentrations of glucose, total and free cholesterol, triacylglycerol, and phospholipid are shown in Table 5. No significant difference was observed between the control and any experimental group. Thus, the serum concentrations of total and free cholesterol, triacylglycerol, phospholipid, and glucose were probably not affected by dietary fiber in the present study, although the rats were not fasted for more than $5 \mathrm{~h}$.

\section{DISCUSSION}

The average molecular weight of Polydextrose is lower than that of natural dietary fiber [1]. Therefore, the effects of Polydextrose on fecal volume and weight, transit time, and softening of feces are considered to be different from those of natural dietary fiber having a high molecular weight. Furthermore, it should be noted that about $25 \%$ of the ingested Polydextrose is digested in the small intestine and/or fermented in the large intestine and utilized as an energy source $[2,3]$. Another distinctive chemical structural feature of Polydextrose is that it is a heterogenous compound with random bonding and is unable to form a gel like other water-soluble dietary fibers. Accordingly, it is conjectured that Polydextrose can not display the physiological action that suppresses the intestinal absorption of glucose, triacylglycerol, and cholesterol, etc. As expected, the biochemical parameters in serum were not affected by Polydextrose ingestion in this study, although such effects might be related to the amount of Polydextrose intake and to the length of the feeding period.

It should be pointed out that excessive consumption of Polydextrose leads to mild gastrointestinal effects similar to those experienced with other poorly digested foods [16]. However, in our preliminary tests, rats suffered strong diarrhea, not mild, by excessive consumption of Polydextrose and did not adapt to this intake for at least several weeks (unpublished data). Therefore, a diet containing a high level of Polydextrose alone as the dietary fiber source could not be used in this animal experiment. Excessive consumption of nondigestible oligosaccharides such as Neosugar and maltitol also causes diarrhea in rat and man $[13,14]$. However, the diarrhea disappears soon upon feeding. The recovery from diarrhea is due to adaptation to the oligosaccharides, which probably changes and increases the intestinal bacteria that can utilize them. The fact that diarrhea was not eliminated by a diet containing 5\% Polydextrose indicates that Polydextrose is resistant to utilization by intestinal bacteria. However, a 3\% level of Polydextrose in the diet did not induce diarrhea. Thus, this level is thought to be a reasonable concentration for the observation of effects on the physiology of the large intestine.

In practice, we should eat many kinds of dietary fiber with various physiological actions. The combination of Polydextrose and either pectin or cellulose appears to be much better than Polydextrose alone in order to improve on fecal 
volume and weight, transit time, and softening of feces. These combinations increased significantly the water-holding capacity of feces and raised the fecal weight. However, they did not show the additional effect of shortening gastrointestinal transit time in spite of the fecal weight increase. The difference may be dependent on the characteristics of Polydextrose. Nakagawa et al. [17] demonstrated that ingestion of $7 \mathrm{~g}$ or $10 \mathrm{~g}$ of Polydextrose daily leads to significantly softened feces, but does not affect the frequency and feeling of the need to defecate in humans.

In conclusion, Polydextrose partially demonstrates the physiological action of dietary fiber, although it was developed as a low energy bulking agent. Therefore, Polydextrose might be categorized as a dietary fiber.

\section{REFERENCES}

1. Allingham, R.P. (1982): Polydextrose-A new food ingredient-Technical aspect, in Chemistry of Food and Beverages: Recent Developments, ed. by Charalambous, G. and Inglett, G., pp. 293-303, Academic Press, New York.

2. Figdor, S.K., and Rennhard, H.H. (1981): Caloric utilization and disposition of $\left[{ }^{14} \mathrm{C}\right]-$ Polydextrose in the rat. J. Agric. Food Chem., 29, 1181-1189.

3. Figdor, S.K., and Rennhard, H.H. (1981): Caloric utilization and disposition of $\left[{ }^{14} \mathrm{C}\right]-$ Polydextrose in man. J. Agric. Food Chem., 31, 389-393.

4. Council on Scientific Affairs (1989): Dietary fiber and health. J. Am. Med. Assoc., 262, 542546.

5. American Institute of Nutrition (1977): Ad Hoc Committee on standards for nutritional studies. J. Nutr., 107, 1340-1348.

6. Dahlquist, A. (1964): Method for assay of intestinal disaccharidases. Anal. Biochem., 7, 1825.

7. Lowry, O.H., Rosebrough, N.J., Farr, A.L., and Randall, R.J. (1951): Protein measurement with Folin phenol reagent. J. Biol. Chem., 193, 265-275.

8. Oku, T., Konishi, F., and Hosoya, N. (1981): Effect of various unavailable carbohydrates and administrating periods on several physiological functions of rats. Nippon Eiyo Shokuryo Gakkaishi (J. Jpn. Soc. Nutr. Food Sci.), 34, 437-443 (in Japanese).

9. Ogi, M., Tanaka, T., Hiraki, K., Takayama, Y., Sonoyama, F., and Shimizu, F. (1985): Automated determination of urea $\mathrm{N}$ and uric acid in urine by OLYMPUS AU-500. J. Jpn. Clin. Liquid. Anal., 10, 222-226 (in Japanese).

10. Yoshizawa, S., Moriuchi, S., and Hosoya, N. (1975): The effect of maltitol on rat intestinal disaccharidases. J. Nutr. Sci. Vitaminol., 21, 31-37.

11. Oku, T., Konishi, F., and Hosoya, N. (1982): Biochemical and morphological changes of gastrointestinal tract by dietary fiber. Nutr. Rep. Int., 28, 643-653.

12. Konishi, F., Oku, T., and Hosoya, N. (1984): Hypertrophic effect of unavailable carbohydrate on cecum and colon in rat. J. Nutr. Sci. Vitaminol, 30, 373-379.

13. Tokunaga, T., Oku, T., and Hosoya, N. (1986): Influence of chronic intake of new sweetener fructooligosaccharide (Neosugar) on growth and gastrointestinal tract of rat. J. Nutr. Sci. Vitaminol., 32, 111-121.

14. Inoue, Y., Moriuchi, S., and Hosoya, N. (1970): Effect of maltitol administration on the development of rats. Nippon Eiyo Shokuryo Gakkaishi (J. Jpn. Soc. Nutr. Food Sci.), 23, 625-629 (in Japanese).

15. Oku, T., Konishi, F., Kanda, A., and Hosoya, N. (1983): Biochemical and morphological changes of gastrointestinal tract by unavailable carbohydrate, in Dietary Fiber-Nutritional

Vol. 11, No. 1, 1991 
and Food Scientific Approach, ed. by Innami, S., Inoue, G., Goto, Y., Hosoya, N., Yoshida, A., and Kiriyama, S., pp. 75-89, Shinohara Publisher, Tokyo (in Japanese).

16. Scrimshaw, N., and Young, V. (1977): A Clinical Metabolic Balance Study with a Polydextrose in Young Adult Subjects. Materials, Pfizer Inc., New York.

17. Nakagawa, Y., Okamatsu, H., and Fujii, Y. (1990): Effects of Polydextrose feeding on the frequency and feeling of defecation in healthy female volunteers. Nippon Eiyo Shokuryo Gakkaishi (J. Jpn. Soc. Nutr. Food Sci.), 43, 955-101 (in Japanese). 